\title{
AVALIAÇÃO DAS CARACTERISTICAS FISICO-QUÍMICAS, MICROBIOLÓGICAS E ROTULAGEM DE LEITE PASTEURIZADO COMERCIALIZADO NA MICRORREGIÃO DE UBÁ - MINAS GERAIS
}

\section{Evaluation physical and chemical characteristics, microbiological and pasteurized milk labeling marketed in Ubá - Minas Gerais}

\author{
Aryane da Luz Oliveira ${ }^{l}$, Neumara Ribeiro Vaneli ${ }^{l}$, Pamela de Oliveira Vargas ${ }^{l}$, \\ Aurélia Dornelas de Oliveira Martins ${ }^{*}$, Elaine Souza Cócaro ${ }^{\text {, }}$ \\ Antônio Daniel Fernandes Coelho ${ }^{I}$
}

\begin{abstract}
RESUMO
Objetivou-se avaliar as características físico-químicas, microbiológicas e a rotulagem de sete marcas de leite pasteurizado comercializados na microrregião de Ubá - Minas Gerais. Foram realizadas análises físico-químicas de acidez, lactose, gordura, proteína, EST, ESD, pH, densidade, ponto crioscópico, umidade e cocção, bem como análises microbiológicas de coliformes totais e termotolerantes e contagem padrão em placas. Para as análises físico-quimicas, foram obtidos os seguintes resultados médios: $16^{\circ} \mathrm{D}(0,16 \mathrm{~g}$ de ácido lático/ $100 \mathrm{~g}$ de produto $)$ para acidez titulável, 4,61\% para lactose, 3,21\% para gordura, 3,11\% para proteína, $11,63 \%$ para EST, 8,39\% para ESD, pH de $6,76,1,030 \mathrm{~g} / \mathrm{mL}$ para densidade relativa a $15^{\circ} \mathrm{C}$, $-0,531{ }^{\circ} \mathrm{H}$ para crioscopia. Das sete amostras analisadas uma apresentou presença de água nos três lotes analisados (média de 4,06\% de água). Cerca de 28,57\% das amostras apresentaram coagulação no teste de cocção. Foi observado diferença significativa $(\mathrm{p}<0,05)$ para a maioria dos parâmetros físico-químicos. Quanto às análises microbiológicas foram encontrados valores variando de $<3,0 \mathrm{NMP} / \mathrm{mL}$ a $>1.100 \mathrm{NMP} / \mathrm{mL}$ tanto para coliformes totais quanto para termotolerantes. Para

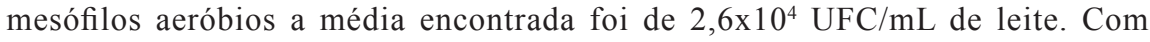
relação à análise de rotulagem apenas duas amostras $(28,57 \%)$ encontraram-se em conformidade com todas as exigências listadas e vigentes para rotulagem de
\end{abstract}

1 Instituto Federal de Educação, Ciência e Tecnologia do Sudeste de Minas Gerais, Campus Rio Pomba, Av. Dr. José Sebastião da Paixão, s/n, Bairro Lindo Vale, 36180-000, Rio Pomba, MG, Brasil. E-mail: aurelia.dornelas@ifsudestemg.edu.br

* Autor para correspondência. 
alimentos. Desta forma, conclui-se que os leites pasteurizados comercializados na microrregião de Ubá apresentam diferenças quanto sua composição físico-química e qualidade microbiológica.

Palavras-chave: legislação, laticínios, saúde pública.

\begin{abstract}
The objective was to evaluate the physical-chemical, microbiological and labeling of seven brands of pasteurized milk marketed in regions near the city of Ubá - Minas Gerais. We performed physical and chemical analyzes of acidity, lactose, fat, protein, EST, ESD, pH, density, cryoscopic point, humidity and cooking, as well as microbiological analysis of total and fecal coliforms and standard plate count. For physical-chemical analyzes, the following average results were obtained: $16^{\circ} \mathrm{D}$ for titratable acidity, $4,61 \%$ for lactose, $3,21 \%$ for fat, $3,11 \%$ for protein, $11,63 \%$ for EST, 8,39\% to ESD, pH 6,76, 1,030g / $\mathrm{ml}$ for specific density at $15^{\circ} \mathrm{C}-0.531{ }^{\circ} \mathrm{H}$ to freezing point. Of the seven samples analyzed one showed the presence of water in three batches analyzed in an average ratio of $4,06 \% ; 28,57 \%$ of the samples were clotting in the cooking test, being observed significant difference $(\mathrm{p}<0.05)$ for most physical and chemical parameters. As for microbiological analyzes we found average $<3,0 \mathrm{NMP} / \mathrm{mL}$ and $>1.100 \mathrm{NMP} / \mathrm{mL}$ for total and fecal coliforms respectively and average 2,6×10 $\mathrm{CFU} / \mathrm{ml}$ for aerobic mesophilic. Regarding the analysis of labeling only two samples $(28,57 \%)$ found to comply with all listed and existing requirements for food labeling. Thus, it is concluded that pasteurized milk marketed in the region of Ubá show differences in their physical and chemical composition and microbiological quality.
\end{abstract}

Keywords: legislation, dairy, human health.

\section{INTRODUÇ̃̃O}

No cenário mundial, o Brasil é o quinto maior produtor de leite, e cresce a uma taxa anual de $4 \%$, superior à de todos os países que ocupam os primeiros lugares. Dessa forma, responde por $66 \%$ do volume total de leite produzido nos países que compõem o MERCOSUL (EMBRAPA, 2012). Esse ramo do agronegócio desempenha um papel importante na geração de emprego e renda, no suprimento alimentar (GUIMARÃES et al., 2006) e na economia de países em desenvolvimento, isso porque além de envolver um componente social é considerado um produto essencial na mesa do consumidor (ZOCCAL; GOMES, 2005).
A cadeia produtiva do leite representa um importante segmento do agronegócio brasileiro e é fundamental para garantir a segurança alimentar da população. A modernização tecnológica, o avanço nas pesquisas, a intensificação das exigências legais e a preocupação do consumidor com a qualidade dos alimentos tem promovido diversas alterações no setor (OLIVEIRA FILHO et al., 2014).

Diversos fatores podem influenciar a demanda de produtos alimentícios, principalmente no setor de lácteos. Dentre eles podem ser citados o aumento da população, a redução dos preços e a mudança dos costumes alimentares. Um exemplo claro disso é a redução significativa do consumo de leite 
pasteurizado e o aumento do consumo do leite longa vida UAT (Ultra Alta Temperatura) devido, principalmente, à facilidade de transporte e armazenamento, uma vez que este tipo de leite não necessita de refrigeração (PAIVA, 2007).

A composição percentual média do leite de vaca de diversas raças européias é: $87 \%$ de água, 4,4\% de gordura, $4,6 \%$ de lactose, $3,3 \%$ de caseína e proteínas do soro, $0,7 \%$ de minerais, $0,17 \%$ de sais e $0,13 \%$ de vitaminas e enzimas. A composição, a cor e o sabor do leite variam de acordo com a espécie leiteira, a raça, idade e dieta do animal, bem como o estádio de lactação, número de parições, sanidade, sistema de exploração, ambiente físico e estação do ano (FAO, 2016).

É necessário que os padrões exigidos pelo Ministério de Agricultura, Pecuária e Abastecimento (MAPA) sejam atendidos para se fornecer leite de boa qualidade (BRASIL, 2011). Atualmente, este é um grande desafio a ser vencido pelos produtores, pela indústria e pelo governo. Neste cenário, o presente estudo tem por objetivo avaliar as características físico-químicas, microbiológicas e de rotulagem de leite pasteurizado comercializado na microrregião de Ubá - Minas Gerais.

\section{MATERIAL E MÉTODOS}

Este trabalho foi desenvolvido em três repetições nos Laboratórios de Microbiologia de Alimentos e de Análise de Alimentos do Departamento de Ciência e Tecnologia de Alimentos do Instituto Federal do Sudeste de Minas Gerais, campus Rio Pomba.

\section{Coleta das amostras}

Sete amostras de leite pasteurizado integral foram coletadas nas cidades mineiras de Tabuleiro, Rio Pomba, Ubá e Visconde do Rio Branco, em três semanas distintas, a fim de se obter lotes diferentes. Imediatamente após a coleta, as amostras foram acondicionadas em recipientes refrigerados e transportadas aos laboratórios.

\section{Análises físico-químicas}

Foram realizadas análises de gordura, sólidos totais e desengordurado, lactose, densidade, proteína, ponto crioscópico e porcentagem de água no analisador de leite marca AKSO. Antes de ser utilizado, o aparelho foi devidamente higienizado com água a temperatura de, aproximadamente, $65^{\circ} \mathrm{C}$ com algumas gotas de detergente neutro, sendo então o modo de limpeza acionado. Logo após a limpeza, as amostras foram devidamente analisadas e os resultados anotados.

As análises de $\mathrm{pH}$ e acidez foram realizadas segundo a Instrução Normativa $n^{\circ} 68$ de 2006 (BRASIL, 2006).

Para análise de cocção, foram adicionados $5 \mathrm{~mL}$ de cada amostra em diferentes tubos de ensaio, levados a chama até ebulição. Foi verificado resultado a partir da presença de coagulação da amostra.

\section{Análises microbiológicas}

Foram realizadas análises microbiológicas de contagem padrão em placas (UFC/mL), coliformes a $30^{\circ} \mathrm{C}$ e a $45^{\circ} \mathrm{C}$, segundo a Instrução Normativa n ${ }^{\circ} 62$ de 2003 (BRASIL, 2003).

\section{Análise de rotulagem}

Os rótulos das amostras foram lavados e secos, sendo analisados conforme parâmetros estabelecidos pela Instrução Normativa $\mathrm{n}^{\mathrm{o}} 22$ de 2005 (BRASIL, 2005), RDC n 360 (ANVISA, 2003b), Lei 11265 (ANVISA, 2006), RDC no 359 (ANVISA, 2003c), Portaria 157 (INMETRO, 2002), Lei 10674 (ANVISA, 2003a). Não foi avaliada legislação 
para alergênicos, uma vez que o experimento foi conduzido antes dessa exigência.

Foram utilizados os seguintes parâmetros: Conteúdo; Nome ou Razão Social; Endereço; CNPJ; Carimbo do Sistema de Inspeção Oficial; Número de Registro no Sistema de Inspeção; Informações sobre cuidado e conservação do produto; Lote; Informações Nutricionais; Frase Obrigatória: "Este produto não deve ser usado para alimentar crianças menores de 1 (um) ano de idade, a não ser por indicação expressa do médico ou nutricionista. $\mathrm{O}$ aleitamento materno evita infecções e alergias e deve ser mantido até a criança completar 2 (dois) anos de idade ou mais".

\section{Análise estatística}

Os resultados obtidos foram submetidos às análises de variância e teste de média (Tukey a 5\% de probabilidade) quando necessário, utilizando-se o programa computacional estatístico SISVAR (FERREIRA, 2000).

\section{RESULTADOS E DISCUSSÃO}

\section{Análises físico-químicas}

Os resultados obtidos quanto a análises físico-químicas são encontrados na Tabela 1.

As amostras A, B, C e G obtiveram uma acidez significativamente $(\mathrm{p}<0,05)$ maior que a amostra $\mathrm{D}$, provavelmente devido a adição de água. As amostras A, B, C, E, F e G não diferiram entre si $(p>0,05)$, assim como as amostras D, E e F ( p > 0,05). A adição de água ao leite pode reduzir sua acidez que, segundo o Regulamento Técnico de Identidade e Qualidade de leite Pasteurizado, deve estar entre 0,14 e $0,18 \mathrm{~g}$ de ácido lático/100 mL (BRASIL, 2011).

De acordo com a tabela, somente a amostra D de leite pasteurizado está fora dos padrões propostos pela legislação vigente.
Beloti et al. (1996), analisando leites pasteurizados na cidade de Londrina - PR, verificaram que $15 \%$ das amostras estavam fora dos padrões estabelecidos para a prova de acidez, ao contrário deste trabalho.

Quanto à análise de lactose, as amostras D e A apresentaram menores valores, sendo que a última não diferiu estatisticamente das amostras B, C e F. As amostras B, C, E, F e $G$, obtiveram um valor significativamente $(\mathrm{p}<0,05)$ maior em relação à amostra $\mathrm{D}$. Esse resultado se relaciona também a fraude com água, uma vez que sua adição "dilui" os componentes sólidos do leite.

Cortez et al. (2010) ao analisarem amostras de leite pasteurizado fraudadas com água e soro observaram que o teor de lactose foi alterado quando esta passou de $1 \%$ comparado com 4,3\% de lactose, constatando que na adição de água, soro fisiológico e glicosado a partir de $1 \%$ já caracteriza uma não conformidade. A mesma tendência de redução da concentração de lactose é observada para a adição de soro de queijo, porém de forma menos marcante devido à presença de carboidratos nestas soluções. A legislação brasileira nada cita sobre os teores de lactose no leite.

As amostras F, A e C não diferiram entre si quanto ao teor de gordura, sendo que as amostras A e C não diferiram das amostras B, D, E e G. Esse resultado pode ser justificado pela falta de padronização nos processos industriais. Das amostras analisadas $71,42 \%$ (cinco amostras) estão dentro dos padrões exigidos pela legislação e 28,57\% (duas amostras) não se adequaram a legislação vigente, estando com teor de gordura abaixo de $3.0 \%$, sem conter no rótulo a especificação semidesnatado ou desnatado.

Cortez et al. (2010) ao analisarem leite pasteurizado com fraude de água e soro perceberam que o teor de gordura apresentouse fora do mínimo determinado pela legislação $(3,0 \%)$. 
Tabela 1 - Valores médios das características físico-químicas das amostras de leite pasteurizado

\begin{tabular}{|c|c|c|c|c|c|c|c|c|c|}
\hline \multirow{2}{*}{ Análises } & \multicolumn{8}{|c|}{ Amostras } & \multirow{2}{*}{$\begin{array}{l}\text { Padrão } \\
\text { Oficial }^{*}\end{array}$} \\
\hline & A & B & $\mathrm{C}$ & $\mathrm{D}$ & $\mathrm{E}$ & $\mathrm{F}$ & $\mathrm{G}$ & $\mathrm{dms}$ & \\
\hline $\begin{array}{c}\text { Acidez } \\
\text { (g ácido lático/ } \\
100 \mathrm{~g} \text { produto) }\end{array}$ & $0,16^{\mathrm{b}}$ & $0,16^{\mathrm{b}}$ & $0,17^{\mathrm{b}}$ & $0,123^{\mathrm{a}}$ & $0,156^{\mathrm{ab}}$ & $0,153^{\mathrm{ab}}$ & $0,183^{b}$ & 0,38 & 0,14 a 0,18 \\
\hline Lactose $(\%)$ & $4,47^{\mathrm{ab}}$ & $4,56^{\mathrm{bc}}$ & $4,71^{\mathrm{bc}}$ & $4,20^{\mathrm{a}}$ & $4,78^{c}$ & $4,70^{\mathrm{bc}}$ & $4,83^{\mathrm{c}}$ & 0,29 & $\mathrm{NE}$ \\
\hline Gordura (\%) & $3,31^{\mathrm{ab}}$ & $3,20^{\mathrm{a}}$ & $3,25^{\mathrm{ab}}$ & $2,78^{a}$ & $3,14^{\mathrm{a}}$ & $3,87^{b}$ & $2,90^{\mathrm{a}}$ & 0,66 & Mín 3,0 \\
\hline Proteína (\%) & $3,03^{\mathrm{b}}$ & $3,08^{\mathrm{bc}}$ & $3,17^{\mathrm{bc}}$ & $2,83^{\mathrm{a}}$ & $3,22^{\mathrm{c}}$ & $3,19^{\mathrm{bc}}$ & $3,24^{\mathrm{c}}$ & 0,17 & $\begin{array}{c}\text { Mín 2,9 } \\
\text { para leite cru }\end{array}$ \\
\hline EST $(\%)$ & $11,42^{\mathrm{a}}$ & $11,40^{\mathrm{a}}$ & $12,01^{\mathrm{a}}$ & $10,60^{\mathrm{a}}$ & $11,88^{\mathrm{a}}$ & $12,47^{\mathrm{a}}$ & $11,60^{\mathrm{a}}$ & 3,0 & $\mathrm{NE}$ \\
\hline ESD (\%) & $8,15^{\mathrm{ab}}$ & $8,32^{\mathrm{bc}}$ & $8,58^{\mathrm{bc}}$ & $7,66^{\mathrm{a}}$ & $8,70^{\mathrm{c}}$ & $8,56^{\text {bc }}$ & $8,79^{c}$ & 0,52 & Mín 8,4 \\
\hline $\mathrm{pH}$ & $6,75^{\mathrm{ab}}$ & $6,75^{\mathrm{ab}}$ & $6,66^{\mathrm{a}}$ & $7,02^{\mathrm{b}}$ & $6,77^{\mathrm{ab}}$ & $6,84^{\mathrm{ab}}$ & $6,54^{\mathrm{a}}$ & 0,32 & NE \\
\hline Densidade & $1,03^{\mathrm{a}}$ & $1,03^{\mathrm{a}}$ & $1,03^{\mathrm{a}}$ & $1,03^{\mathrm{a}}$ & $1,03^{\mathrm{a}}$ & $1,03^{\mathrm{a}}$ & $1,03^{\mathrm{a}}$ & 0 & NE \\
\hline $\begin{array}{c}\text { Índice } \\
\text { Crioscópico } \\
* *(\mathrm{oH})\end{array}$ & $-0,513$ & $-0,524$ & $-0,542$ & $-0,492$ & $-0,550$ & $-0,544$ & $-0,555$ & - & $-0,530$ a $-0,550$ \\
\hline Água (\%) & 0 & 0 & 0 & 4,06 & 0 & 0 & 0 & - & Não permitido \\
\hline
\end{tabular}

Médias seguidas de pelo menos uma mesma letra na linha não diferem entre si ao nível de $5 \%$ de probabilidade pelo teste de Tukey; dms: Diferença mínima significativa; ESD = Extrato Seco Desengordurado; EST = Extrato Seco Total; *De acordo com a Instrução Normativa nº 62 (BRASIL, 2011); NE: não existe.

Segundo o Regulamento Técnico de Identidade e Qualidade de Leite pasteurizado o teor de gordura varia de acordo com a classificação do leite em integral, semidesnatado e desnatado, sendo respectivamente os padrões preconizados de no mínimo 3,0, de 0,6 a 2,9 e máximo de 0,5 g/100g (BRASIL, 2011).

Quanto ao teor de proteína, 90\% (seis amostras) apresentaram-se de acordo com os padrões e apenas uma amostra (D) estava com teor inferior ao limite mínimo estabelecido. A legislação brasileira estabelece um mínimo de 2,9\% de proteína para leite cru refrigerado (BRASIL, 2011), porém seus teores podem variar entre 3,0 e 3,8\% (DAIRY PROCESSING HANDBOOK, 2003). Estes resultados podem ser influenciados por fatores como condições climáticas, doenças do animal, estágio de lactação, número de parições, raça, alimentação e teor energético da alimentação, ou podem indicar diluição do leite pela adição de água (SILVA, 1997).

Agenas et al. (2003) encontraram redução na porcentagem de lactose e de proteína bruta do leite, ao submeter os animais a 48 horas de restrição alimentar. Segundo Peres (2001), dentre os fatores que reduzem o teor de proteína estão o baixo consumo de minerais, falta de proteína degradável e falta de carboidratos não estruturais. Para Cortez et al. (2010) a influência das fraudes na concentração de proteína apenas se tornou mais evidente a partir de uma adição de $15 \%$ de água, com o teor de proteína obtido ligeiramente abaixo de $2,9 \%$, que é o valor mínimo aceito pela legislação (BRASIL, 2002). 
Pode-se perceber diante dos resultados que não houve diferença significativa entre as amostras com relação ao teor de extrato seco total. Segundo Zocche et al., (2002) em um estudo sobre leite pasteurizado no Oeste do Paraná, encontraram $8(50 \%)$ e $14(87,5 \%)$ amostras em desacordo com a legislação para extrato seco total.

A soma das quantidades dos componentes do leite, com exceção da água, é chamada de extrato seco total (EST), que é de aproximadamente $12 \%-13 \%$ e que constituem-se de componentes como gordura, carboidrato, proteína, sais minerais e vitaminas (FOSCHIERA, 2004). O extrato seco total diminuído da quantidade de gordura é chamado extrato seco desengordurado (ESD), que é de aproximadamente 8,5\%-9\% (FOSCHIERA, 2004). A utilização de instrumento apropriado permite determinar o teor de extrato seco total por meio dos valores de densidade e do teor de gordura (BRASIL, 2006).

A percentagem de matéria seca ou extrato seco é indispensável para se avaliar a integridade de um leite. Admite-se no leite normal um mínimo de $11,41 \%$ de extrato seco total (FOSCHIERA, 2004).

$\mathrm{Na}$ análise de ESD (extrato seco desengordurado), a amostra D obteve menor valor quando comparado as amostras B, C, E, F e G. A legislação brasileira preconiza um mínimo de 8,4 g/100g de ESD (BRASIL, 2011). Portanto, 42,85\% (três amostras) encontram-se com teor inferior ao valor mínimo preconizado pela legislação vigente.

Teores baixos de sólidos não gordurosos podem indicar teor de proteína baixo, além de possível adição de água. Os sólidos não gordurosos do leite correspondem à fração composta por proteína, lactose e minerais, incluindo as vitaminas, os macro e micro minerais e outros elementos traços.

Garcia et al., (2006), em um trabalho referente à qualidade do leite pasteurizado tipo A, B e C em Campinas, constataram que $83,3 \%$ das amostras estavam com padrões acima dos determinados pela legislação para extrato seco desengordurado.

A amostra D apresentou $\mathrm{pH}$ significativamente maior $(p<0,05)$ que o das amostras C e G. Esse resultado pode ser correlacionado também com a adição de água ou de outros redutores de acidez a esta amostra. A água apresenta $\mathrm{pH}$ próximo da neutralidade e quando adicionada ao leite aumenta significativamente o seu $\mathrm{pH}$. Entretanto a legislação não preconiza valores de $\mathrm{pH}$, sendo que, os que se apresentaram muito desiguais resultaram da fraude com água.

Moysés; Carvalho; Hoffman (2009), ao analisarem amostras de leite pasteurizado comercializado no município de queimadas - PB, observaram que o $\mathrm{pH}$ foi o parâmetro que mais se apresentou fora dos padrões estabelecidos, totalizando assim 24 amostras de um total de 32.

Segundo Silva (1997) para o leite proveniente de diversas fontes, após misturado, o pH varia entre 6,6 e 6,8 . No caso da secreção após o parto (colostro), o pH varia de 6,25 no primeiro dia a 6,46 no terceiro. $O$ leite proveniente de animais com mamite é levemente alcalino, podendo atingir $\mathrm{pH}$ 7,5. O leite apresenta considerável efeito tampão, especialmente em $\mathrm{pH}$ entre 5 e 6 .

Um desequilíbrio do $\mathrm{pH}$ pode ocasionar a redução/aumento da vida de prateleira (visto que isso significa ter havido um aumento no grau de fermentação e as condições de equilíbrio ácido-base foram alteradas), acerto/ erro de formulação e aprovação/reprovação dos produtos de acordo com as normas em vigência (CASTANHEIRA, 2010). Os valores de $\mathrm{pH}$ e acidez do leite não são proporcionais, embora haja uma relação inversa; ou seja, à medida que a acidez se eleva, ocorre abaixamento do $\mathrm{pH}$. A dificuldade na obtenção de uma boa correlação está ligada ao fato de que na determinação da acidez são 
quantificados os prótons hidrogênio livres (íons) e acessíveis (ionizáveis/dissociáveis); por outro lado, apenas os prótons hidrogênio livres (íons) são quantificados na determinação do pH (LORENZETTI, 2006).

$\mathrm{O} \mathrm{pH}$ do leite durante o aquecimento tem forte influencia sobre o grau de associação das soroproteínas com as micelas de caseína. Quando o pH está abaixo de 6,8, a maioria das soroproteínas complexadas estão associadas a superfície das micelas. No momento em que o pH ultrapassa 6,8, além dos agregados de soroproteína migrarem para o soro, ocorre também a dissociação da k-caseína micelar (SINGH, 2004). Valores de $\mathrm{pH}$ acima de 7,0, tornam o fosfato de cálcio menos solúvel, reduzindo assim a concentração de cálcio, o que aumenta a estabilidade térmica do leite (NEGRI, 2002).

Os sólidos do leite, tais como as proteínas, os citratos e os fosfatos atuam como tampões, isto é, são substâncias que estabilizam o $\mathrm{pH}$ do leite, mantendo a faixa normal (entre 6,5 e 6,7) frente a adição de ácidos ou bases diluídas (VELLOSO, 1998).

Um dos redutores de acidez mais utilizados é o bicarbonato de sódio (SILVA et al., 1997). Conforme legislação nacional (BRASIL, 2002), não é permitida a adição de conservantes, substâncias capazes de corrigir o pH, de aditivos ou de substâncias coadjuvantes de tecnologia/elaboração no leite cru.

Quanto à densidade, não houve diferença significativa $(\mathrm{p}<0,05)$ entre as amostras avaliadas. Os resultados apresentaram-se todos de acordo com a legislação vigente que preconiza $1,033 \mathrm{~g} / \mathrm{ml}$ em condições normais na sua composição (BRASIL, 2011).

Cortez et al., (2010) verificaram que a densidade só foi alterada quando a adição de água ultrapassou $25 \%$ ocorrendo, assim, uma redução do valor da densidade da amostra $(1,026 \mathrm{~g} / \mathrm{mL})$ a níveis de não conformidade, segundo a legislação, que determina a faixa de densidade aceitável de 1,028 a 1,034 g/mL (BRASIL, 2002).

Seu valor é função de dois grupos de substâncias: de um lado a concentração de elementos em solução e suspensão e de outro a porcentagem de gordura (PANCOTTO, 2011). Pela determinação de densidade é possível suspeitar se o leite foi desnatado ou aguado. Por outro lado, o valor da densidade combinado com a determinação da percentagem de gordura permite determinar o valor do extrato seco total. A água apresenta densidade de $1 \mathrm{~g} / \mathrm{mL}$, sendo a gordura menos densa que a água e os sólidos não gordurosos mais densos. Dessa forma, a densidade do leite depende do balanço desses componentes.

Há causas de variações normais da densidade que não afetam a qualidade, como a composição do leite em relação ao teor de gordura, o valor proteico e a sua temperatura no momento da determinação. Dentre as causas anormais de variação da densidade, pode-se destacar a adição de água, que leva a uma diminuição na densidade do leite. Já o desnate e a adição de amido faz a densidade aumentar (AGNESE et al., 2002).

Para Calderón et al. (2006) valores muito altos de densidade indicam falta de proteína e energia. Por outro lado, valores muito baixos representam indícios de adição de água com intuito de fraudar o leite aumentando seu rendimento aparente. Além desse fato, há outro agravante, que é a contaminação por bactérias e produtos químicos carreados pela água. A adição de água também reduz o valor nutricional do leite porque altera a relação dos seus constituintes (SILVA et al., 2008).

Segundo a legislação brasileira, o resultado aceitável para o ponto crioscópico do leite situa-se entre $-0,530{ }^{\circ} \mathrm{H}$ e $-0,550{ }^{\circ} \mathrm{H}$ (BRASIL, 2011) para leite pasteurizado. Portanto, $57,14 \%$ dos produtos (quatro amostras) se adequaram aos padrões, sendo que os $42,85 \%$ restantes (três amostras) obtiveram resultados abaixo do permitido decorrente de 
fraudes com água ou reconstituintes fazendo assim o ponto crioscópico se aproximar de $0^{\circ} \mathrm{H}$, ponto de congelamento da água.

Segundo Castanheira (2010) resultados acima de $-0,530{ }^{\circ} \mathrm{H}$ significam adição de água, já resultados abaixo de $-0,560^{\circ} \mathrm{H}$, podem indicar problema de congelamento do leite no tanque de expansão. De acordo com os mesmos autores, resultados de crioscopia baixa também podem indicar adulteração do leite por reconstituintes.

Das sete amostras avaliadas uma apresentou presença de água nos três lotes distintos analisados em uma proporção média de 4,06\%. Segundo a legislação vigente não é permitida à adição de água ao leite, caracterizando assim falha no processamento ou fraude (BRASIL, 2011).

Zooche et al. (2002) constataram 6 $(37,5 \%)$ amostras em desacordo com a legislação vigente para crioscopia. Barbosa et al., (2007) estudando as características físico-químicas do leite cru e pasteurizado consumido no município de Queimadas - PB, observaram que o leite cru não apresentou valores aceitáveis para os parâmetros analisados de acordo com a legislação, exceto para a acidez titulável e densidade. Desta forma, os autores concluíram que há necessidade de adoção de medidas que visem melhorar a qualidade do leite cru antes e depois de submetê-lo a qualquer tratamento térmico.

Das sete amostras analisadas duas apresentaram coagulação fina quando submetidas ao teste de cocção. A estabilidade térmica do leite refere-se á capacidade de processamento do leite para suportar altas temperaturas sem visível coagulação ou geleificação (SINGH, 2004), em determinado pH e temperatura. Essa estabilidade está relacionada à capacidade do leite de resistir à coagulação pelo calor e, portanto, interfere diretamente no processamento industrial (FONSECA; SANTOS, 2007).

A baixa estabilidade térmica do leite é um problema encontrado com frequência em vários estados do Brasil, sendo considerado um fator limitante, principalmente, da matéria-prima utilizada para fabricação do leite UHT, o qual representa $74 \%$ do mercado de leite fluido do Brasil. O tratamento térmico do leite visa garantir a segurança do consumidor e aumentar o tempo de conservação, o que é obtido por meio da redução de microrganismos patogênicos e deterioradores, assim como da atividade enzimática (FONSECA; SANTOS, 2007).

Alguns fatores afetam a estabilidade térmica do leite, dentre elas, as alterações físico-químicas indesejáveis no leite que podem ocorrer com o tratamento térmico, como: deslocamento de cálcio e fosfato solúveis na fase coloidal (precipitação de fosfato tri cálcio), diminuição da solubilidade da proteína do soro e desdobramento da lactose em ácidos orgânicos, entre outras (FONSECA; SANTOS, 2007).

\section{Análises microbiológicas}

A média dos resultados das análises microbiológicas está representada na Tabela 2.

A contagem padrão em placas ou contagem de aeróbios mesófilos em um produto alimentício reflete a qualidade da matéria-prima, bem como as condições de processamento, manuseio e estocagem, permitindo estimar a vida de prateleira do alimento em questão.

A legislação brasileira preconiza para leite pasteurizado contagem padrão em placas de, no máximo, 8,0 x $10^{4} \mathrm{UFC} / \mathrm{mL}$ (BRASIL, 2011). Desta forma, todas as amostras analisadas encontravam-se dentro dos padrões. A baixa temperatura a qual o leite é armazenado e transportado é de grande importância para o controle de multiplicação destes microrganismos. Os valores encontrados podem aumentar se o consumidor não armazenar o produto na temperatura adequada. 
Tabela 2 - Média dos resultados das análises microbiológicas de mesófilos aeróbios e coliformes $30^{\circ} \mathrm{C}$ e $45^{\circ} \mathrm{C}$ do leite pasteurizado

\begin{tabular}{|c|c|c|c|c|}
\hline \multirow{2}{*}{ Amostras } & \multirow{2}{*}{ Repetições } & \multicolumn{3}{|c|}{ Microrganismos avaliados } \\
\hline & & ${ }^{1}$ Mesófilos aeróbios & ${ }^{2}$ Coliformes $30^{\circ} \mathrm{C}$ & ${ }^{2}$ Coliformes $45^{\circ} \mathrm{C}$ \\
\hline A & 1 & $6,5 \times 10^{4}$ & $<3,0$ & $<3,0$ \\
\hline $\mathrm{A}$ & 2 & $1,4 \times 10^{4}$ & $<3,6$ & $<3,0$ \\
\hline $\mathrm{A}$ & 3 & $6,6 \times 10^{4}$ & $<3,0$ & $<3,0$ \\
\hline $\mathrm{B}$ & 1 & $2,5 \times 10^{2}$ & $<3,0$ & $<3,0$ \\
\hline $\mathrm{B}$ & 2 & $8,2 \times 10^{3}$ & $<3,0$ & $<3,0$ \\
\hline $\mathrm{B}$ & 3 & $1,1 \times 10^{4}$ & $<3,0$ & $>1.100 \boldsymbol{\Delta}$ \\
\hline $\mathrm{C}$ & 1 & $8,7 \times 10^{4}$ & $240 \Delta$ & $460 \Delta$ \\
\hline $\mathrm{C}$ & 2 & $2,5 \times 10^{3}$ est & $>1.100 \boldsymbol{\Delta}$ & $9,2 \mathbf{\Delta}$ \\
\hline $\mathrm{C}$ & 3 & $7,7 \times 10^{4}$ & $9,2 \mathbf{\Delta}$ & $<3,0$ \\
\hline $\mathrm{D}$ & 1 & $7,1 \times 10^{4}$ & $<3,0$ & $93 \boldsymbol{\Lambda}$ \\
\hline $\mathrm{D}$ & 2 & $8,8 \times 10^{4}$ & $1.100 \Delta$ & $<3,0$ \\
\hline $\mathrm{D}$ & 3 & $2,4 \times 10^{4}$ & $<3,0$ & $<3,0$ \\
\hline $\mathrm{E}$ & 1 & $2,1 \times 10^{4}$ & $<3,0$ & $<3,0$ \\
\hline $\mathrm{E}$ & 2 & $7,0 \times 10^{3}$ & 3,0 & $<3,0$ \\
\hline $\mathrm{E}$ & 3 & $3,2 \times 10^{3}$ & $<3,0$ & $<3,0$ \\
\hline $\mathrm{F}$ & 1 & $6,5 \times 10^{3}$ & $<3,0$ & $11 \boldsymbol{\Delta}$ \\
\hline $\mathrm{F}$ & 2 & $5,3 \times 10^{4}$ & $93 \Delta$ & $<3,0$ \\
\hline $\mathrm{F}$ & 3 & $9,5 \times 10^{3}$ & 3,0 & $<3,0$ \\
\hline G & 1 & $1,3 \times 10^{2}$ est & $<3,0$ & $<3,0$ \\
\hline G & 2 & $1,3 \times 10^{4}$ & $9,2 \mathbf{\Delta}$ & $<3,0$ \\
\hline G & 3 & $4,0 \times 10^{2}$ & $<3,0$ & $<3,0$ \\
\hline $\begin{array}{l}\text { Padrão } \\
\text { Oficial* }\end{array}$ & & Máx $8,0 \times 10^{4}$ & Máx 4 & Máx 2 \\
\hline
\end{tabular}

*De acordo com a Instrução Normativa n ${ }^{0} 62$ (BRASIL, 2011); est: estimado; ${ }^{1} \mathrm{UFC} / \mathrm{mL} ;{ }^{2} \mathrm{NMP} / \mathrm{mL}$; $\boldsymbol{\Delta}$ : fora dos padrões legais vigentes.

Salvador et al., (2012), ao analisarem seis amostras de leite tipo B e C comercializados em Apucarana e região observaram que todas as amostras estavam de acordo com os parâmetros para contagem de mesófilos aeróbios, resultado semelhante ao do presente estudo. Oliveira Filho et al. (2014) determinaram contagens de mesófilos aeróbios no leite cru e encontraram valores entre 1,2 x $10^{6}$ e $3,0 \times 10^{6} \mathrm{UFC} / \mathrm{mL}$, acima dos valores recomendados pela legislação vigente.

A análise de coliformes nos alimentos é de grande importância para a indicação de contaminação durante o processo de fabricação ou mesmo pós-processamento. Segundo Franco e Landgraf (2005), os 
microrganismos indicadores são grupos ou espécies que, quando presentes em alimentos, podem fornecer informações sobre a ocorrência de contaminação fecal e a provável presença de patógenos e deterioradores. Presença de coliformes em leite pasteurizado pode indicar pasteurização ineficiente, recontaminação após tratamento térmico ou higiene inadequada de equipamentos, utensílios e embalagens (THIELMANN; ARCURI, 1999).

De acordo com a instrução normativa $n^{0} 62$, para o leite pasteurizado ser considerado apto para consumo deve apresentar contagem de coliformes $30^{\circ} \mathrm{C}$ de, no máximo, $4 \mathrm{NMP} / \mathrm{mL}$ e contagem de coliformes a $45^{\circ} \mathrm{C}$ de, no máximo, $2 \mathrm{NMP} / \mathrm{mL}$ (BRASIL, 2011). Portanto, das diferentes amostras e lotes analisados, 57,14\% (quatro amostras, em pelo menos um dos lotes) apresentaram níveis superiores ao permitido pela legislação de coliformes a $30^{\circ} \mathrm{C} \mathrm{e} 45^{\circ} \mathrm{C}$.

Vieira et al. (2002) verificaram que, das 99 amostras de leite pasteurizado analisadas, 49,5\% (49 amostras) encontraram-se fora dos padrões estabelecidos pela legislação.

\section{Rotulagem}

Todas as amostras apresentaram o conteúdo (1 litro) descrito no painel principal conforme a instrução normativa 22 de 2005 (BRASIL, 2005) que aprova o Regulamento Técnico sobre Rotulagem de Alimentos Embalados. As embalagens também apresentaram caracteres legíveis e precedidos pela palavra "CONTÉM" ou "CONTEÚDO" ou "CONT.", conforme estabelecido pela Portaria INMETRO n ${ }^{\circ} 157$, de 19 de agosto de 2002 (INMETRO, 2002).

Apenas duas amostras $(28,57 \%)$ encontraram-se em conformidade com todas as exigências vigentes para rotulagem de alimentos (Tabela 3). Dentre as amostras coletadas, $5(71,42 \%)$ não atenderam a essas exigências em pelo menos um dos requisitos listados. Dois dos sete rótulos não apresentavam o nome ou razão social, conforme estabelecido pela Instrução Normativa $\mathrm{n}^{\mathrm{o}} 22$ de 2005 (BRASIL, 2005).

Uma amostra não apresentou endereço, três não apresentaram CNPJ e carimbo do Sistema de Inspeção Oficial e número de registro no órgão competente. Duas amostras apresentaram falha quanto a informações de cuidado e conservação do produto. Duas não continham identificação do lote. A Instrução Normativa $n^{\circ} 22$ de 2005 (BRASIL, 2005), estabelece que todo rótulo deverá ter impresso, gravado ou marcado de qualquer outro modo, uma indicação em código ou linguagem clara, que permita identificar o lote a que pertence o produto de origem animal, de forma que seja visível, legível e indelével.

Das amostras avaliadas, três tiveram falha quanto às informações nutricionais obrigatórias. Segundo a RDC no 359, de 23 de dezembro de 2003 (ANVISA, 2003c), os consumidores possuem o direito de ter informações sobre as características e composição nutricional dos alimentos que adquirem.

Duas amostras estavam inconformes em relação a frase obrigatória estabelecida pela Lei $n^{\circ} 11265$ de 3 de janeiro de 2006 (ANVISA, 2006). A referida lei estabelece que os rótulos desses produtos deverão exibir no painel principal, de forma legível e de fácil visualização, o seguinte destaque: AVISO IMPORTANTE: Este produto não deve ser usado para alimentar crianças menores de 1 (um) ano de idade. O aleitamento materno evita infecções e alergias e é recomendado até os 2 (dois) anos de idade ou mais.

Outros autores também verificaram inconformidades em rótulos de produtos, especialmente no que se refere á lácteos.

Dias, Prado e Godoy (2008) avaliando rótulos de leite em pó, encontraram não conformidades em $90 \%$ das amostras. 
Tabela 3 - Inadequações em rótulos de leite pasteurizado comercializado na microrregião de Ubá - MG

Item verificado

Marcas dos rótulos inadequados

Conteúdo

Nome ou razão social

Endereço

CNPJ, Carimbo do Sistema de Inspeção Oficial, Número de registro

Informações sobre cuidado e conservação do produto

Lote

Informações nutricionais

Frase obrigatória

nenhuma
F e G
F
C, F e G
F e G
F e G
A, B, F e G
F e G

Enquanto Santana e Penha Filho (2009), verificaram que $10 \%$ dos rótulos de leites UHT em Salvador - BA, não indicavam o percentual de gordura trans, informação nutricional obrigatória.

Silva e Nascimento (2007), ao analisarem 20 rótulos de iogurtes comercializados no Rio de Janeiro, observaram que 70\% dos rótulos apresentavam algum tipo de não conformidade.

As informações contidas, nos rótulos, devem ser claras a fim de serem utilizadas para orientar a escolha adequada de alimentos (CÂMARA et al., 2008) e atender a legislação vigente.

\section{CONCLUSÕES}

Os leites pasteurizados comercializados na microrregião de Ubá - MG apresentaram composição físico-química variável, sendo observada adição de água em uma amostra, o que não é permitido pela legislação.

A qualidade microbiológica dos leites quanto a mesófilos aeróbios apresentou-se dentro dos padrões vigentes, porém, quanto a contagem de coliformes, quatro amostras, em pelo menos um dos lotes apresentaram níveis superiores ao permitido pela legislação, caracterizando más condições higiênico-sanitária durante a fabricação, visto que estes microrganismos são indicadores de qualidade higiênica.

Apesar dos órgãos regulamentadores imporem exigências para rotulagem de alimentos em geral, alguns beneficiadores de leite fluido, ainda não atendem integralmente a essa legislação como foi possível observar diante dos resultados obtidos. Recomendase, portanto maior preocupação e instrução, no sentido de atender integralmente os parâmetros estabelecidos pela lei. Ressalta-se também a importância da atuação por parte dos órgãos fiscalizadores, visto que, todos os itens exigidos na rotulagem têm sua importância e, portanto, devem estar contidos nos rótulos.

\section{REFERÊNCIAS}

AGENAS, S. et al. Changes in metabolism and milk production during and after feed deprivation in primiparous cows selected for different milk fat content. Livestock Production Science, v. 83, p. 153-164, 2003.

AGNESE, A. P. et al. Avaliação físico-química do leite cru comercializado informalmente 
no Município de Seropédica - RJ. Revista Higiene Alimentar, v. 16, n. 94. p. 58-61, 2002.

AGÊNCIA NACIONAL DE VIGILÂNCIA SANITÁRIA (ANVISA). LEGISLAÇÃO. VISALEGIS. Lei n ${ }^{\circ} 10674$, de 16 de maio de 2003. Obriga a que os produtos alimentícios comercializados informem sobre a presença de glúten como medida preventiva e de controle da doença celíaca. Diário Oficial da República Federativa do Brasil, Brasília, maio 2003a. Disponível em: <http://www. camara.gov.br/proposicoesWeb/prop_mo strarintegra codteor $=440852 \&$ filename $=$ LegislacaoCitada+-PL+336/2007>. Acesso em: 22 jun. 2016.

AGÊNCIA NACIONAL DE VIGILÂNCIA SANITÁRIA (ANVISA). Resolução RDC $\mathrm{n}^{\circ} 360$, de 23 de dezembro de 2003. Regulamento Técnico sobre Rotulagem Nutricional de Alimentos Embalados. Diário Oficial da União, Brasília, 26 dez. 2003 b.

AGÊNCIA NACIONAL DE VIGILÂNCIA SANITÁRIA (ANVISA). Resolução RDC $n^{\circ} 359$, de 23 de dezembro de 2003. Regulamento Técnico de porções de alimentos embalados para fins de rotulagem nutricional. Diário Oficial da União, Brasília, 23 dez. 2003c.

AGÊNCIA NACIONAL DE VIGILÂNCIA SANITÁRIA (ANVISA). Lei $n^{\circ} 11265$, de 3 de janeiro de 2006. Regulamenta a comercialização de alimentos para lactentes e crianças de primeira infância e também a de produtos de puericultura correlatos. Diário Oficial da República Federativa do Brasil, Brasília, 04 jan. 2006.

BARBOSA, A. S. et al. Características físico-químicas e microbiológicas do leite cru e pasteurizado consumido no município de
Queimadas, PB. In: 1., Congresso NorteNordeste de Química, 2007, Natal. Anais... Natal, 2007.

BELOTI, V. et al. Aspectos físico-químicos do leite pasteurizado tipo c consumido na cidade de Londrina. In: CONGRESSO BRASILEIRO DE MEDICINA VETERINÁRIA, 24. 1996, Goiânia. Anais... Goiânia: Sociedade Goiana de Veterinária, 1996. p. 205.

BRASIL. Ministério da Agricultura, Pecuária e Abastecimento. Departamento de Inspeção de Produtos de Origem Animal. Instrução Normativa $n^{\circ} 51$, de 18 de setembro de 2002. Coleta de leite cru refrigerado e seu transporte a granel. Diário Oficial da República Federativa do Brasil, Brasília, 20 set. 2002, Seção 1, p. 8-13.

BRASIL. Ministério da Agricultura Pecuária e Abastecimento, Departamento de Inspeção de Produtos de Origem Animal. Instrução Normativa $\mathrm{n}^{\circ} 62$, de 26 de agosto de 2003 oficializa os Métodos Analíticos Oficiais para Análises Microbiológicas para Controle de Produtos de Origem Animal e Água. Diário Oficial da União, Brasília, 18 set. 2003.

BRASIL, Ministério da Agricultura, Pecuária e Abastecimento. Departamento de Inspeção de Produtos de Origem Animal. Instrução Normativa $\mathrm{n}^{\circ} 22$, de 24 de novembro de 2005: Regulamento Técnico para Rotulagem de Produto de Origem Animal Embalado. Diário Oficial da República Federativa do Brasil, Brasília, 25 nov. 2005.

BRASIL. Ministério da Agricultura e Pecuária e Abastecimento. Departamento de Inspeção de Produtos de origem Animal. Instrução Normativa $\mathrm{n}^{\circ} 68$ de 12 de dezembro de 2006. Métodos analíticos oficiais físico-químicos, para controle de leite e produtos lácteos. 
Diário Oficial da República Federativa do Brasil, Brasília, 14 dez. 2006.

BRASIL, Ministério da Agricultura, Pecuária e Abastecimento. Departamento de Inspeção de Produtos de Origem Animal. Instrução Normativa $n^{\circ}$ 62, de 29 de dezembro de 2011. Altera a Instrução Normativa MAPA n ${ }^{0} 51$, 18 de setembro de 2002. Diário Oficial da República Federativa do Brasil, Brasília, dez., 2011.

CALDERÓN, A. et al. Indicadores de calidad de leches crudes em diferentes regiones de Colômbia. Revista M. V. Z. Córdoba, v. 11, p. $725-737,2006$.

CÂMARA, M. C. C. et al. Análise crítica da rotulagem de alimentos diet e light no Brasil. Caderno Saúde Coletiva, (Rio J.), n. 1, v. 16, p. 35-52, 2008.

CAStAnHEIRA, A. C. G. Manual Básico de Controle de Qualidade de Leite e Derivados - comentado. São Paulo: Cap Lab, 2010. 276 p.

CORTEZ, M. A. S. et al. Características físico-químicas e análise sensorial do leite pasteurizado adicionado de água, soro de queijo, soro fisiológico e soro glicosado. Revista do Instituto de Laticínios Cândido Tostes, v. 65, n. 376, p. 18-25, 2010.

DAIRY PROCESSING HANDBOOK. $2^{\mathrm{a}}$ ed. Tetra Pak. 2003. 440p.

DIAS, F. F. G. et al. Avaliação da rotulagem nutricional obrigatória em embalagens segundo o padrão da ANVISA. Revista Analytica, n. 34, p. 56-67, 2008.

Empresa Brasileira de Pesquisa Agropecuária - EMBRAPA Gado de Leite. Disponível em: $<$ HYPERLINK http://www.cnpgl.embrapa. br/novas/informacoes/estatistica/producao/ producao.php www.cnpgl.embrapa.br/novas/ informacoes/estatistica/producao/producao. php. Acesso em: 11 jun. 2012.

FAO. Composição do leite. Disponível em: <http://www.fao.org>. Acesso em: 08 abr 2016.

FERREIRA, D. F. Análises estatísticas por meio do Sisvar para Windows 4.0. In: REUNIÃO ANUAL BRASILEIRA DA SOCIEDADE INTERNACIONAL DE BIOMETRIA, 45., São Carlos, 2000. Anais... São Carlos, Universidade Federal de São Carlos, 2000. p. 255-258.

FONSECA, L. F. L; SANTOS, M. V. Estrategias para controle de mastite e melhoria da qualidade do leite. Barueri, Manole, 2007. 314p.

FOSCHIERA, J. L. Indústria de laticínios: Industrialização do leite, análises, produção de derivados. Porto Alegre: Suliani, 2004.

FRANCO, B. D. G. M; LANDGRAF, M. M. T. D. Microbiologia dos Alimentos. São Paulo, Atheneu, 2005. p. 27-171.

GARCIA, A. O. et al. Avaliação da Qualidade Físico-Química e Microbiológica do Leite Pasteurizado Tipos A, B e C Comercializa-dos em Campinas - SP. Higiene Alimentar, São Paulo, v. 21, n. 150, p. 131-132, 2006.

GUIMARÃES, G. F. et al. Desempenho do setor leiteiro no Brasil, 1990 a 2004. Revista do Instituto de Laticínios Cândido Tostes, v. 61, n. 351, p. 279-281, 2006.

INMETRO. Legislação. Regulamentos técnicos. Portaria n ${ }^{\circ} 157$, de 19 de agosto de 2002. Estabelecer a forma de expressar a 
indicação quantitativa do conteúdo líquido dos produtos pré-medidos. Disponível em $<$ http://www.inmetro.gov.br/legislacao/rtac/ pdf/RTAC000786.pdf>. Acesso em: 22 jun. 2016 .

LORENZETTI, D. K. Influência do tempo e da temperatura no desenvolvimento de micro-organismos psicrotróficos no leite cru de dois estados da região sul. 2006. $71 \mathrm{f}$. Dissertação (Mestrado em Tecnologia de Alimentos) - Universidade Federal do Paraná, Curitiba, 2006.

MOYSÉS, J, B. et al. Avaliação físicoquímica do leite pasteurizado tipo c produzido e comercializado na região de Tangará da Serra - MT, Brasil - Estudo de Caso. Revista do Instituto de Laticínios Cândido Tostes, v. 366, p. 22-27, 2009.

NEGRI, L. M. R. Estudo de Los factores fisicoquimicos de La leche cruda que incidem sobre La estabilidad térmica. Santa Fé-Argentina, 180f. Dissertação (mestrado dos alimentos) - Faculdade de Ingeníeria química, Universidad Nacional Del Litoral, 2002.

OLIVEIRA FILHO, J. G. et al. Cadernos de Agroecologia, v. 9, n. 4, p. 1-5, 2014.

PAIVA, R. M. B. Avaliação físico-química e microbiológica de leite pasteurizado tipo c distribuído em programa social governamental. 2007. 76f. Dissertação (Mestrado em Medicina Veterinária) - Universidade Federal de Minas Gerais, Belo Horizonte, 2007.

PANCOTTO, A. P. Análise das características físico-químicas e microbiológicas do leite produzido no Instituto Federal de Educação, Ciência e Tecnologia do Rio Grande do Sul - campus Bento Gonçalves. 2011.
34 f. TCC (Trabalho de Conclusão de curso em Tecnologia em Alimentos) - Instituto Federal de Educação, Ciência e Tecnologia do Rio Grande do Sul, Bento Gonçalves, 2011.

PERES, J. R. O leite como ferramenta do monitoramento nutricional. In: GONZALEZ, F. H. D.; DURR, J. W.; FONTANELI, R. S. (Ed.). Uso do Leite para monitorar a nutrição e metabolismo de vacas leiteiras. Porto Alegre: Ed. Da UFRGS, 2001. p. 29-43.

SALVADOR, F. C. et al. Avaliação da qualidade microbiológica do leite pasteurizado comercializado em Apucarana - PR e região. Revista F@pciência, v. 9, n. 5, p. 30-41, 2012.

SANTANA, M. L. A. C; PENHA FILHO, M. L. Avaliação da rotulagem nutricional e estudo comparativo entre marcas de produtos lácteos encontrados em supermercados de Salvador - BA. Higiene Alimentar, v. 23, n. 170/171, p. 578, 2009.

SILVA, E. B.; NASCIMENTO, K. O. Avaliação da adequação da rotulagem de iogurtes. Ceres: Nutrição \& Saúde, n. 2, p. 9-14, 2007.

SILVA, M. C. D. et al. Caracterização microbiológica e físico-química de leite pasteurizado destinado ao programa do leite no Estado de Alagoas. Ciência e Tecnologia de Alimentos, Campinas, v. 28, n. 1, p. 226$230,2008$.

SILVA, P. H. F. et al. Físico-química do leite e derivados: métodos analíticos. $1^{\mathrm{a}} \mathrm{ed}$. Oficina de Impressão Gráfica e Editora Ltda., 1997. $190 \mathrm{p}$.

SILVA, P. H. F. Leite: Aspectos de composição e propriedades. Química e Sociedade. Química Nova na Escola, São Paulo, n. 6, p. 3-5, 1997. 
SINGH, H. Heart stability of Milk. International Journal of Dairy Technology, v. 57, p. 111-119, 2004.

THIELMANN, C. ARCURI, E. F. Métodos Microbiológicos básicos e aplicados a leite e derivados. Cândido Tostes: EPAMIG/CT Instituto de Laticínios, 1999.

VELLOSO, C. R. V. Noções básicas da acidez. In: BRITTO, J. R. F.; DIAS, J. C. (Ed). A qualidade do leite. Juiz de Fora: Embrapa CNPGL; São Paulo: Tortuga, 1998. p. 37-45.

VIEIRA, M. C. M. et al. Avaliação micro- biológica do leite pasteurizado tipo $\mathrm{C}$, comercializado no estado de Goiás no período de janeiro a junho de 2000 . Revista de patologia tropical, v. 31, p. 77-86, 2002.

ZOCCAL, R.; GOMES, A. T. Tendências da produção de leite no Brasil. In: CONGRESSO NACIONAL DE LATICÍNIOS, 22, Juiz de Fora. Anais... EPAMIG/ILCT: ILCT, 2005. 1 CD-ROM.

ZOCCHE, F. et al. Qualidade Microbiológica e Físico-Química do Leite Pasteurizado produzido na região oeste do Paraná. Arch. Vet. Sci., v. 7, n. 2, p. 59-67, 2002. 